\title{
Avaliação do Perfil dos Acidentes Fatais Ocorridos nas Rodovias Federias de Santa Catarina em 2015 e sua Utilização para Direcionar Ações que Visem Reduzir a Violência no Trânsito
}

\author{
Gabriela Almeida Marcon 1 \\ Luiz Antonio Giardino Graziano ${ }^{2}$ \\ Fernanda Aparecida Da Cunha ${ }^{3}$ \\ Ademar Dutra 4 \\ Leonardo Ensslin 5 \\ Universidade do Sul de Santa Catarina - UNISUL
}

\begin{abstract}
RESUMO
Este trabalho tem por objetivo discutir o perfil dos 368 acidentes de trânsito fatais ocorridos nas rodovias federais de Santa Catarina no ano de 2015 e propor ações que reduzam esse tipo de acidente. É um estudo de caso, com pesquisa bibliográfica e coleta de dados dos acidentes no sistema SIGER 2 da Polícia Rodoviária Federal e nos boletins de acidentes de trânsito lavrados. Os resultados mostram que houve um custo de mais de 244 milhões de reais somente com esses acidentes; as rodovias BR 101, 282 e 470 concentraram $77 \%$ dos acidentes fatais do Estado, sendo que a BR 101 foi responsável por 68\% das mortes por atropelamento no Estado; 60\% dos pedestres mortos tinham mais de 40 anos e 77\% dessas mortes ocorreram no período noturno (das 18 às 6 horas da manhã). Os motociclistas representaram $18 \%$ do total de mortes, sendo que $60 \%$ dos motociclistas mortos tinham até de 40 anos e $74 \%$ das motos tinham até 150 cilindradas. Em relação aos ciclistas mortos, $57 \%$ tinham mais de 40 anos e $64 \%$ das mortes foram no período noturno (das 18 às 6 horas da manhã). Em 47\% das mortes, um dos veículos envolvidos era de carga, pesado (caminhões, etc). As ações para reduzir a violência no trânsito não devem se resumir ao aumento de penalidade administrativa ou judicial; as ações devem englobar múltiplas áreas, levando em conta os três pilares de um trânsito seguro: educação, engenharia e fiscalização.
\end{abstract}

Palavras-chave: Acidentes rodoviários; Trânsito; Política Pública; Polícia Rodoviária Federal. ABSTRACT

This paper aims to outline the profile of the 368 fatal traffic accidents on federal highways of Santa Catarina in 2015 and propose actions to reduce this type of accident. It is a case study, with bibliographic research and data collection on accidents system of the Federal Highway Police called SIGER 2 and bulletins issued traffic accidents. The results show that there was a cost of over 244 million reais with these accidents; the highways BR 101, 282 and 470 concentrated $77 \%$ of the state's fatal accidents, and the BR 101 accounted for $68 \%$ of deaths from trampling in the state; $60 \%$ of pedestrians killed were over 40 and $77 \%$ of these deaths occurred at night (from 18 to $6 \mathrm{am}$ ). Motorcyclists accounted for $18 \%$ of all deaths, $60 \%$ of motorcyclists killed were up to 40 and $74 \%$ of the bikes had up to $150 \mathrm{cc}$. Regarding the cyclists killed, 57\% were over 40 and $64 \%$ of deaths were at night (from 18 to 6 am). In $47 \%$ of all deaths, one vehicle was truck. Actions to reduce violence in traffic should not be limited to the increase in administrative or judicial penalty; actions must encompass multiple areas, taking into account the three pillars of a safe traffic: education, engineering and enforcement.

Keywords: Road accidents; Traffic; Public policy; Federal Highway Police.

\footnotetext{
${ }^{1}$ Discente do Programa de Pós-graduação em Administração da UNISUL

${ }^{2}$ Discente do Programa de Pós-graduação em Administração da UNISUL

${ }^{3}$ Discente do Programa de Pós-graduação em Administração da UNISUL

${ }^{4}$ Docente do Programa de Pós-graduação em Administração da UNISUL

${ }^{5}$ Docente do Programa de Pós-graduação em Administração da UNISUL
} 


\section{RESUMEN}

Este trabajo tiene por objetivo discutir el perfil de los 368 accidentes de tránsito fatales ocurridos en las carreteras federales de Santa Catarina en el año 2015 y proponer acciones que reduzcan ese tipo de accidente. Es un estudio de caso, con investigación bibliográfica y recolección de datos de los accidentes en el sistema SIGER 2 de la Policía Rodoviária Federal y en los boletines de accidentes de tránsito labrados. Los resultados muestran que hubo un costo de más de 244 millones de reales sólo con esos accidentes; las carreteras BR 101, 282 y 470 concentraron el 77\% de los accidentes fatales del Estado, siendo que la BR 101 fue responsable del 68\% de las muertes por atropellamiento en el Estado; El 60\% de los peatones muertos tenían más de 40 años y el 77\% de esas muertes ocurrieron en el período nocturno (de las 18 a las 6 de la mañana). Los motociclistas representaron el 18\% del total de muertes, mientras que el $60 \%$ de los motociclistas muertos tenían hasta 40 años y el 74\% de las motos tenían hasta 150 cilindradas. En cuanto a los ciclistas muertos, el 57\% tenía más de 40 años y el 64\% de las muertes fueron en el período nocturno (de las 18 a las 6 de la mañana). En el 47\% de las muertes, uno de los vehículos involucrados era de carga, pesado (camiones, etc). Las acciones para reducir la violencia en el tránsito no deben resumirse en el aumento de penalidad administrativa o judicial; las acciones deben englobar múltiples áreas, teniendo en cuenta los tres pilares de un tránsito seguro: educación, ingeniería y fiscalización.

Palabras clave: Accidentes de tráfico. Tránsito. Política Pública. Policía Federal de Carreteras.

\section{Introdução}

A violência nas rodovias é assunto preocupante. Estatísticas acerca de acidentes de trânsito há tempos têm um papel fundamental no planejamento do tráfego e delineamento de medidas de segurança no trânsito, por esta razão despertam tanto interesse dos pesquisadores (Bull \& Roberts, 1973; Limpert, 1984; Miaou \& Lum, 1993; Horn \& Reyner, 1999; Beck; Dellinger \& O’neil, 2007).

De acordo com a Organização Mundial da Saúde, 1,3 milhão de pessoas morreram no mundo no ano de 2009 em decorrência de acidentes de trânsito. A Organização das Nações Unidas (ONU), a fim de reduzir esses números alarmantes, decretou, em nível mundial, a Década de Ação pela Segurança no Trânsito - 2011 - 2020, lançada em 11 de maio de 2011.

No ano de 2004, em todo o mundo, os acidentes de trânsito foram a primeira causa de mortes entre jovens de 15 a 29 anos, a segunda causa de mortes de pessoas entre 5 e 14 anos e a terceira causa entre adultos de 30 a 44 anos (Who, 2009). Na Espanha, os acidentes de trânsito foram a primeira causa de mortes entre pessoas de 15 a 34 anos, no ano de 2011 (Instituto de Salud Carlos III, 2013).

A violência no trânsito atinge todo o Brasil, inclusive o Estado de Santa Catarina, o qual figura entre os mais violentos no trânsito brasileiro, sobretudo nas rodovias federais. Segundo pesquisa realizada com base em análise de dados do Sistema de Informação sobre Mortalidade do Ministério da Saúde e divulgada pela USP, apenas em 2013, o Brasil apresentou mais de 170 mil internações hospitalares em função de acidentes de trânsito. Homens jovens, de 20 a 39 anos, motociclistas e moradores do Centro-Oeste e do Nordeste brasileiro, no referido ano, foram os mais atingidos (USP, 2016).

O Estado catarinense tem nove rodovias federais, totalizando aproximadamente 2.400 quilômetros. O policiamento das rodovias federais compete à Polícia Rodoviária Federal - PRF, enquanto que a conservação da via é responsabilidade do órgão executivo rodoviário da União, o DNIT - Departamento Nacional de Infraestrutura de Transportes, ou à ANTT - Agência Nacional de Transporte Terrestre, nas rodovias concedidas.

O estudo de causas de acidentes e seu atendimento fazem parte das atribuições da PRF. Vários fatores influenciam na prevenção de acidentes, dentre os quais podemos citar a infraestrutura, o comportamento humano e a fiscalização. Esses três fatores são conhecidos internacionalmente como os três pilares de um trânsito seguro ou os 3 E's (Engineering, Enforcement e Education, ou Engenharia, Esforço legal ou fiscalização e Educação, respectivamente).

Os dados decorrentes dos boletins de acidentes de trânsito geram indicadores de desempenho no âmbito da PRF, e estes ressaltam algumas características presentes em grande parte dos acidentes. Uma análise dessas características comuns a vários acidentes pode gerar proposições para a redução da violência no trânsito, seja em termos de engenharia, fiscalização ou educação. Normalmente as ações governamentais frente a problemas de conduta contrária ao ordenamento jurídico limitam-se à criminalização da conduta, recrudescimento de pena judicial ou das penalidades administrativas, sem ação concreta consoante os três pilares mencionados. 
Os acidentes de trânsito geram grandes custos diretos, indiretos e intangíveis para o país. Um estudo do IPEA demonstra que os acidentes com mortos são os que geram maiores custos para a sociedade; em média um acidente fatal no Brasil custa $\mathrm{R} \$ 664.821,46$. Assim, analisando o perfil dos acidentes fatais ocorridos nas rodovias federais em Santa Catarina no ano de 2015, poderemos sugerir algumas proposições para reduzir esse tipo de acidente e os acidentes em geral.

A pergunta que surge, então, é: Que ações para reduzir a violência no trânsito podem ser adotas pela sociedade a partir da análise do perfil dos acidentes fatais que ocorreram nas rodovias federais de Santa Catarina no ano de 2015?

O objetivo geral desse trabalho é discutir quais espécies de ações que visem reduzir a violência no trânsito podem ser sugeridas a partir do estudo do perfil dos acidentes fatais ocorridos nas rodovias federais de Santa Catarina no ano de 2015.

Para atingir esse objetivo foram traçados os seguintes objetivos específicos: (i) realizar um estudo documental descritivo dos acidentes fatais ocorridos nas rodovias federais de Santa Catarina no ano de 2015, destacando suas características; (ii) identificar circunstâncias comuns aos acidentes estudados; (iii) apontar os danos causados pelos acidentes; (iv) indicar proposições que tenham potencial de influenciar na redução da violência do trânsito a partir dos achados.

O estudo tem sua justificativa e importância na medida em que a violência decorrente do trânsito gera grandes prejuízos financeiros e não financeiros para toda a sociedade. Assim, estudar o perfil dos acidentes fatais e discutir ações para redução da violência no trânsito trará benefícios para todos os usuários do sistema e também para não usuários, haja vista que os recursos dispendidos com vítimas de acidentes de trânsito refletem negativamente em outros usuários do sistema de saúde, por exemplo, que não acidentados no trânsito.

Esse artigo está dividido em cinco seções: Seção 1 - Introdução; Seção 2 - Referencial teórico; Seção 3 - Metodologia; Seção 4 - Resultados e Seção 5 - Conclusões e recomendações.

\section{Referencial Teórico}

Acidentes rodoviários acarretam grande risco à incolumidade pública (Peden et al., 2004; Who, 2013; Rowe et al., 2015). Muitas são as possíveis causas de acidentes, grande parte deles causado por comportamento ou falhas humanas, tais como sonolência, estresse, distúrbios visuais ou auditivos, uso do celular e outros equipamentos eletrônicos (Selzer; Rogers \& Kern, 1968; Horne \& Reyner, 1999; Nemme \&White, 2010; Wilson \& Stimpson, 2010; Harrison, 2011; Hoff et al., 2013).

Os números de acidentes e vítimas de acidentes de trânsito no Brasil são controversos, porquanto a forma de registro de acidentes não é unificada e nem padronizada. Conta-se com vários órgãos que atendem ocorrências desse tipo, cada um fazendo o registro dentro de banco de dados próprio. Um estudo sobre causas de acidentes em Curitiba/PR apontou como limitação à pesquisa, além da disjunção, a falta de qualidade dos dados sobre acidentes de trânsito (Barreto et al., 2016).

Segundo o site oficial do governo brasileiro, Portal Brasil, no ano de 2013 ocorreram 42.266 mortes vítimas de acidentes de trânsito no Brasil. Esse número é extremamente alto: morrem, em média, 115 pessoas por dia em acidentes de trânsito no Brasil ou 4,8 pessoas por hora. Nas rodovias federais do país morreram 6.868 pessoas no ano de 2015 em acidentes de trânsito, segundo dados fornecidos pela PRF e divulgados no jornal Folha de São Paulo. Em Santa Catarina, no ano de 2015, morreram 455 pessoas nas rodovias federais do Estado, vítimas de acidentes de trânsito, segundo levantamento feito no sistema SIGER 2 da PRF e leitura dos boletins de acidentes de trânsito. Levantamentos da PRF indicam que Santa Catarina foi o quarto Estado com o maior número de mortes em rodovias federais no ano de 2014 (537 mortes), quando

\footnotetext{
Avaliação do Perfil dos Acidentes Fatais Ocorridos nas Rodovias Federias de Santa Catarina em 2015 e sua Utilização para Direcionar Ações que Visem Reduzir a Violência no Trânsito

Gabriela Almeida Marcon, Luiz Antonio Giardino Graziano, Fernanda Aparecida Da Cunha, Ademar Dutra e Leonardo Ensslin
} 
8.227 pessoas perderam a vida nas rodovias federais brasileiras. Em 2014, como tem ocorrido todos os anos, Minas Gerais foi o estado com o maior número de mortes nas rodovias federais do Brasil.

Grande parte dos mortos em acidentes de trânsito são pedestres, ciclistas e motociclistas, que são os usuários mais frágeis do sistema trânsito. O Código de Trânsito Brasileiro (CTB) traz essa preocupação com esse grupo de usuários quando impõe a norma geral no artigo $29, \S 2^{\circ}$, nos seguintes termos: "Respeitadas as normas de circulação e conduta estabelecidas neste artigo, em ordem decrescente, os veículos de maior porte serão sempre responsáveis pela segurança dos menores, os motorizados pelos não motorizados e, juntos, pela incolumidade dos pedestres."

Estudo realizado em Campinas/SP sobre acidentes de trânsito ocorridos entre 2000 e 2008 mostrou que $49 \%$ dos acidentes fatais envolvia motos e concluiu que, apesar da moto ser uma eficiente ferramenta de transporte, principalmente em grandes centros urbanos, é um veículo extremamente frágil para condutor e passageiro (Barreto et al., 2016).

Um estudo realizado no município de São Paulo/SP relativo a todos os acidentes envolvendo motos (11.366 acidentes) e bicicletas (1.558 acidentes) de janeiro de 2011 a outubro de 2013 revelou que os acidentes com motos corresponderam a $52 \%$ de todos os acidentes notificados e os acidentes com bicicletas corresponderam a 7\%. A faixa etária predominante nos acidentes com motos foi entre 20 e 29 anos (46\%) e nos acidentes com bicicletas a faixa predominante foi entre 10 e 19 anos (39\%). Os acidentes com motos e bicicletas ocorreram com maior frequência entre 7 e 18 horas (37\% e 27\%, respectivamente) (Rodrigues et al., 2014).

Segundo o anuário estatístico de 2006 do DENATRAN, foram registradas 19.910 vítimas fatais em acidentes de trânsito naquele ano no Brasil, sendo que 22\% (4.395 mortos) eram pedestres, 16\% (3.243) eram motociclistas e $6 \%(1,243)$ eram pedestres.

Acidentes com veículos pesados de carga normalmente são graves, independente de culpa. Assim como os atropelamentos de pedestres são graves por envolver um veículo e uma pessoa, acidentes envolvendo veículos de grande porte como caminhões e combinações de veículos de carga (carreta, bitrem, etc) normalmente são acidentes graves, com vítimas. Um estudo nos Estados Unidos da América mostrou os benefícios de separar o fluxo de veículos leves e pesados (caminhões) em rodovias, em termos de segurança, mobilidade e custo em geral (De Palma; Kilani \& Lindsey, 2008).

Os acidentes fatais são os que geram mais prejuízos para a sociedade. O IPEA - Instituto de Pesquisa Econômica Aplicada, em sua Estimativa de Custos dos Acidentes de Trânsito no Brasil com Base na Atualização Simplificada das Pesquisas Anteriores do IPEA (Brasília, 2015), concluiu que um acidente fatal em rodovia federal do Brasil custa $R \$ 664.821,46$, enquanto que um acidente com ferido custa $R \$ 96.747,79$ e um acidente sem vítima custa $R \$ 23.498,77$. Os acidentes fatais, portanto, além dos custos intangíveis, são os que oneram mais a sociedade e o Estado financeiramente, motivos que ensejam seu estudo e propostas para reduzi-los.

O estudo das causas e características dos acidentes de trânsito, sua gravidade e periculosidade das rodovias, podem contribuir efetivamente para o alcance dos objetivos estratégicos da Polícia Rodoviária Federal e melhoria dos serviços prestados à população. São poucos os estudos sobre causas de acidentes de trânsito no Brasil, apesar da sua grande importância. Levantar causas de acidentes de trânsito é um trabalho bastante difícil, conforme afirma Renato Mendes Fonseca, perito criminal do Estado do Tocantins, em pesquisa que realizou sobre o assunto e concluiu que $40 \%$ dos acidentes pesquisados foram causados por invasão da pista contrária, porém não conseguiu elucidar os motivos que levaram o condutor a praticar tal ato, por ser de difícil verificação e englobar várias causas possíveis. Também são poucos os estudos sobre psicologia do trânsito no Brasil, existindo a necessidade de pesquisas nessa área, o que contribuiria bastante para a redução da violência no trânsito (DE OLIVEIRA, et al., 2015).

Alguns estudos demonstram que a redução da violência no trânsito exige medidas em diversas áreas, passando, necessariamente, pelos 3 (três) pilares de um trânsito seguro, conhecidos internacionalmente como 3 E's - Engineering, Enforcement e Education. No Brasil, os três pilares são traduzidos como Engenharia, Esforço legal ou fiscalização e Educação. Entretanto, para determinarmos ações nesses três pilares e que 
venham a influenciar positivamente na redução da violência do trânsito, faz-se necessário estudar as características dos acidentes ocorridos e, a partir desses dados, propor ações que ataquem as circunstâncias que contribuíram para a ocorrência desses acidentes (Almeida, 2006).

Estudo sobre acidentes de trânsito em Curitiba, relativo aos acidentes ocorridos de 1996 a 2011, aponta que houve uma redução do coeficiente de mortalidade para homens e mulheres, sendo que as prováveis causas estariam relacionadas a campanhas educativas midiáticas, projeto de cunho internacional de redução da violência do trânsito implantado especificamente em Curitiba e o aumento do rigor da legislação em relação à embriaguez ao volante (Barreto et al., 2016).

$\mathrm{Na}$ Espanha, uma pesquisa sobre violência no trânsito na Comunidade Valenciana, mostrou que houve uma redução significativa de mortes nos últimos 25 anos, sobretudo na segunda metade da década de 2.000, em ambos os sexos. Essa redução ocorreu a partir de um conjunto de medidas, como ações de engenharia para tornar as rodovias mais seguras, decisão do governo de priorizar ações de segurança no trânsito, implementação de um sistema de punição rígido para infratores no trânsito, com ênfase ao controle de velocidade, embriaguez e uso de drogas no volante, e campanhas de educação de trânsito. (Melchor et al., 2015).

Infelizmente, é bastante comum no Brasil a não adoção de um conjunto de medidas multidisciplinares para solução de problemas graves, sobretudo medidas que exijam investimentos financeiros e que tenham resultados a médio e longo prazo. Normalmente os governantes brasileiros adotam medidas que tragam resultados a curto prazo, mas que não atuam na causa do problema e, em consequência, não o resolvem. Buscam medidas ligadas a mudanças legislativas, aumentando a punição de condutas reprováveis, sem alterar as condições físicas, econômicas, sociais e culturais da população e do ambiente envolvido. Logicamente que a alteração legislativa, recrudescendo as penalidades ou penas daqueles que praticam condutas nocivas à sociedade (crime ou infração administrativa, por exemplo), deve ocorrer, mas se a única medida efetiva for essa, o problema persistirá. Isso tem sido recorrente no combate à criminalidade, onde o direito penal tem sido usado como única forma de tentar reprimir comportamentos criminosos (De Deus, 2015). A simples majoração de penas dos crimes não reduz criminalidade (Tondo et al., 2014).

Isso também ocorreu quando da edição do atual CTB - Código de Trânsito Brasileiro, em 1997; fruto de um clamor público contra o elevado número de vítimas de acidentes de trânsito, houve alteração legislativa que aumentou significativamente as penalidades de infrações e criminalizou várias condutas, como embriaguez ao volante, por exemplo. Entretanto, a alteração legislativa necessária à época, por não vir acompanhada de outras medidas necessárias, não resolveu o problema da violência do trânsito.

\section{Metodologia}

A proposta desse artigo é realizar um estudo de caso a partir de documentos, acerca do perfil dos acidentes fatais ocorridos nas rodovias federais em Santa Catarina no ano de 2015 e discutir ações para sua redução.

Um estudo de caso é um meio de organizar dados sociais preservando o caráter unitário do objeto social estudado, analisa-se intensivamente uma situação particular (Goode \& Hatt, 1969; Tull, 1976).

O caráter do estudo é quali-quantitativo. A pesquisa qualitativa, segundo Martins (2004), é uma forma intensiva de examinar dados, tanto amplitude quanto profundidade, tratando assim das unidades sociais investigadas pelo pesquisador. Para Lakatos e Marconi (2003), um estudo quantitativo-descritivo é uma forma de descobrir as variáveis pertinentes ao objetivo do trabalho e também a relação relevante entre as variáveis. 
Foi realizada inicialmente uma pesquisa bibliográfica, com objetivo de expandir o conhecimento sobre a temática do caso a ser estudado (Lakatos \& Marconi, 2003).

O estudo, quanto à coleta de dados, é transversal, eis que os dados são referentes aos acidentes fatais ocorridos em nove rodovias federais em Santa Catarina no ano de 2015. A coleta teve como fonte o sistema SIGER 2, ferramenta utilizada pela Polícia Rodoviária Federal para armazenar dados de acidentes de trânsito e os 368 boletins de acidentes fatais lavrados. Dessa forma, consegue-se ter informação com alto grau de confiabilidade visto que foram apontadas pelo órgão responsável direto pelo acompanhamento dos acidentes ocorridos em rodovias federais. No estudo referido, restrito aos dados das rodovias federais catarinenses, as informações foram obtidas nos boletins de acidentes de trânsito lavrados, sendo levantadas as seguintes informações: Data, hora, BR, Município, km, Tipo de acidente, Veículos envolvidos, Mortos, Idade e número da ocorrência no sistema.

\section{Resultados}

O estudo das causas e características de acidentes de trânsito em rodovias federais é uma das funções da PRF. A instituição é, atualmente, responsável pelo policiamento e fisscalização de mais de sessenta mil quilômetros de rodovias federais que viabilizam o direito constitucional de livre locomoção ao redor do país. Foi instituída, originariamente, pelo presidente Washington Luiz, em 1928, a partir do Decreto n. 18.323, com a denominação inicial de "Polícia de Estradas" (Brasil, 2015).

A PRF nos moldes atuais surge após a promulgação da Constituição Cidadã de 1988. A Lei Federal n. 9.654/98 cria a carreira de policial rodoviário federal (Brasil, 1998). É uma instituição policial presente em todo o território nacional, estruturada em 21 Superintendências Regionais, subdivididas em Distritos Regionais, Delegacias e Postos de Fiscalização. A administração central é sediada em Brasília-DF. Sua missão de realizar o ao patrulhamento ostensivo das rodovias federais está disposta no artigo 144 , $\S 2^{\circ}$, da Constituição da República. Objetivando elucidar esta função constitucional, outros dispositivos legais também tratam mais detidamente da matéria, a exemplo do artigo 20 do Código de Trânsito Brasileiro (Lei $\mathrm{n}^{\circ}$ 9.503/97).

Entre as atividades da PRF está a fiscalização do cumprimento do Código de Trânsito Brasileiro, objetivando acautelar e refrear os abusos cometidos ao volante, como excesso de velocidade e embriaguez, além de prestar atendimento às vítimas de acidentes. Não bastasse, também é a PRF responsável por auxiliar no combate à criminalidade, colaborando com a segurança pública (Leite, 2013).

Os acidentes de trânsito ocorrem nas rodovias federais, nas rodovias estaduais e nas vias urbanas dos municípios. Nas rodovias federais os acidentes são registrados pela Polícia Rodoviária Federal (PRF); nas rodovias estaduais normalmente o registro é feito pelas Polícias Militares Rodoviárias dos Estados e nas vias urbanas dos municípios o registro é feito pelas Polícias Militares ou agentes de trânsito municipais. Ressalte-se, entretanto, que muitos acidentes sem vítimas são registrados via internet em diversos órgãos, outros são registrados diretamente na Polícia Civil e o atendimento de acidentes é feito por instituições como Corpo de Bombeiros Militar dos Estados, SAMU, Concessionárias de rodovias e por outros órgãos que operam na área de prestação de atendimento de urgência.

Nesta pesquisa, considera-se apenas dados de acidentes ocorridos em rodovias federais no Estado de Santa Catarina. Todos as informações de acidentes ocorridos nas rodovias federais de Santa Catarina foram extraídas do banco de dados da Polícia Rodoviária Federal, por meio do sistema SIGER 2 e dos 368 boletins de acidentes fatais lavrados. Santa Catarina tem 9 (nove) rodovias federais, que totalizam, aproximadamente, 2.400 quilômetros. Nas rodovias federais do Estado, no ano de 2015, foram registrados 13.945 acidentes, 2.142 feridos graves, 7.513 feridos leves e 455 mortos (Tabela 1 ).

Tabela 1 - Número de acidentes, feridos graves, feridos leves e mortos nas rodovias federais de Santa Catarina no ano de 2015 


\begin{tabular}{|c|c|c|c|c|}
\hline Ano: 2015 & Acidentes & Feridos graves & Feridos leves & Mortos \\
\hline BR 101 & 7.101 & 791 & 3.639 & 128 \\
\hline BR 116 & 697 & 134 & 388 & 39 \\
\hline BR 153 & 177 & 23 & 110 & 9 \\
\hline BR 158 & 51 & 15 & 30 & 3 \\
\hline BR 163 & 127 & 25 & 65 & 6 \\
\hline BR 280 & 1.163 & 272 & 671 & 45 \\
\hline BR 282 & 2.327 & 450 & 1.309 & 109 \\
\hline BR 470 & 2.205 & 414 & 1.242 & 114 \\
\hline BR 480 & 97 & 18 & 59 & 2 \\
\hline TOTAL & 13.945 & 2.142 & 7.513 & 455 \\
\hline
\end{tabular}

Fonte: Elaboração dos autores, 2016.

Os acidentes podem ser classificados em acidentes sem vítimas (apenas danos matérias), acidentes com vítimas (feridos leves e graves) e acidentes com mortos (pelo menos um morto). Há uma outra classificação de acidentes que está sendo utilizada por algumas instituições, como a PRF, que leva em consideração o acidente grave, que é aquele acidente em que ocorreu pelo menos um ferido grave ou um morto. Esta denominação de acidente grave vem ganhando força por ser um dos acidentes que mais geram custos para o Poder Público.

Para fins de embasamento das análises seguintes, é importante consignar que o IPEA - Instituto de Pesquisa Econômica Aplicada, em sua Estimativa de Custos dos Acidentes de Trânsito no Brasil com Base na Atualização Simplificada das Pesquisas Anteriores do IPEA (Brasília, 2015), concluiu que os acidentes de trânsito em rodovias federais apresentam os seguintes custos:

- Acidente com fatalidade - custo médio de $\mathrm{R} \$ 664.821,46$

- Acidente com vítimas - custo médio de $\mathrm{R} \$ 96.747,79$

- Acidente sem vítimas - custo médio de $\mathrm{R} \$ 23.498,77$

Os acidentes fatais nas rodovias federais de Santa Catarina no ano de 2015 representaram um grande custo para toda a sociedade. Considerando que um acidente fatal em rodovia federal custa $R \$$ 664.821,46, segundo cálculos do IPEA, os 368 acidentes fatais ocorridos e pesquisados nesse trabalho, representaram um prejuízo financeiro de $\mathrm{R} \$ 244.654 .297,28$ ou seja, apenas os acidentes fatais ocorridos nas rodovias federais de Santa Catarina no ano de 2015 custaram mais de 244 milhões para a sociedade brasileira, além dos custos intangíveis dos acidentes fatais.

Verifica-se que o custo de um acidente com vítima fatal é muito maior do que os demais acidentes, razão pela qual o estudo foi realizado sobre o perfil dos acidentes fatais ocorridos nas rodovias federais de Santa Catarina no ano de 2015 e, a partir daí, sugerir algumas ações que possam reduzir a violência no trânsito. O levantamento realizado mostrou que ocorreram 368 acidentes fatais nas rodovias federais de Santa Catarina no ano de 2015, os quais geraram 455 mortes (Tabela 2).

Tabela 2 - Distribuição dos mortos em acidentes em 2015 - rodovias federais de Santa Catarina 


\begin{tabular}{|c|c|c|c|c|c|c|}
\hline & $\begin{array}{c}\text { Mortos } \\
\text { (geral) }\end{array}$ & $\begin{array}{c}\text { Acidentes } \\
\text { fatais }\end{array}$ & $\begin{array}{c}\text { Pedestr } \\
\text { es } \\
\text { mortos }\end{array}$ & $\begin{array}{c}\text { Motociclist } \\
\text { as mortos }\end{array}$ & $\begin{array}{c}\text { Mortos em } \\
\text { acidente } \\
\text { envolvendo } \\
\text { veículo de carga } \\
\text { pesado }\end{array}$ & $\begin{array}{c}\text { Ciclista } \\
\text { s } \\
\text { mortos }\end{array}$ \\
\hline Janeiro & 39 & 28 & 7 & 4 & 18 & 0 \\
\hline Fevereiro & 22 & 20 & 1 & 7 & 8 & 0 \\
\hline Março & 53 & 33 & 1 & 9 & 29 & 2 \\
\hline Abril & 28 & 25 & 3 & 6 & 15 & 3 \\
\hline Maio & 32 & 29 & 4 & 7 & 14 & 5 \\
\hline Junho & 43 & 38 & 10 & 7 & 25 & 3 \\
\hline Julho & 40 & 33 & 7 & 7 & 19 & 1 \\
\hline Agosto & 29 & 26 & 6 & 3 & 9 & 1 \\
\hline Setembro & 41 & 36 & 9 & 10 & 15 & 1 \\
\hline Outubro & 25 & 20 & 4 & 4 & 17 & 0 \\
\hline Novembro & 48 & 35 & 5 & 8 & 24 & 3 \\
\hline Dezembro & 55 & 45 & 6 & 10 & 23 & 3 \\
\hline TOTAL & 455 & 368 & 63 & 82 & 216 & 22 \\
\hline
\end{tabular}

Fonte: Elaboração dos autores, 2016.

Se levarmos em consideração que em 2015 ocorreram 368 acidentes fatais nas rodovias federais de Santa Catarina e levarmos em consideração o custo de um acidente fatal divulgado pelo IPEA, concluiremos que houve um custo (ou prejuízo) de $\mathrm{R} \$ 244.654 .297,28$ somente com acidentes fatais nas rodovias federais de Santa Catarina no ano de 2015. Foram mais de 244 milhões de reais gastos só com acidentes fatais.

A Tabela 2 mostra, ainda, que dos 455 mortos nas rodovias federais de Santa Catarina no ano de 2015, 18\% eram motociclistas, 14\% eram pedestres e 5\% eram ciclistas. Além disso, 47\% das mortes ocorreram em acidentes envolvendo veículos de carga pesados (caminhões, carretas, bitrens, etc).

\subsection{Mortes por Rodovia}

Em relação às mortes por rodovia (Tabela 3), verifica-se que $28 \%$ das mortes ocorreram na BR 101, única rodovia duplicada do Estado e que apresenta o maior volume de veículos. Se considerarmos as rodovias BR 101, 470 e 282, verificaremos que essas três rodovias foram responsáveis por $77 \%$ das mortes (351 mortes). $\mathrm{O}$ mês de dezembro foi o que registrou o maior número de mortes.

Tabela 3 - Mortes por rodovia, por mês, em 2015 - rodovias federais de Santa Catarina

\begin{tabular}{|l|c|c|c|c|c|c|c|c|c|c|}
\hline & BR & BR & BR & BR & BR & BR & BR & BR & BR & TOTAL \\
$\mathbf{1 0 1}$ & $\mathbf{1 1 6}$ & $\mathbf{1 5 3}$ & $\mathbf{1 5 8}$ & $\mathbf{1 6 3}$ & $\mathbf{2 8 0}$ & $\mathbf{2 8 2}$ & $\mathbf{4 7 0}$ & $\mathbf{4 8 0}$ & \\
\hline Janeiro & 7 & 4 & 1 & 0 & 2 & 3 & 15 & 7 & 0 & 39 \\
\hline Fevereiro & 6 & 0 & 0 & 1 & 1 & 1 & 6 & 7 & 0 & 22 \\
\hline Março & 10 & 8 & 4 & 0 & 1 & 8 & 12 & 10 & 0 & 53 \\
\hline Abril & 9 & 4 & 0 & 0 & 0 & 4 & 5 & 6 & 0 & 28 \\
\hline Maio & 10 & 1 & 0 & 1 & 0 & 2 & 8 & 10 & 0 & 32 \\
\hline Junho & 13 & 1 & 1 & 0 & 0 & 10 & 8 & 10 & 0 & 43 \\
\hline Julho & 13 & 1 & 0 & 0 & 1 & 3 & 7 & 14 & 1 & 40 \\
\hline Agosto & 10 & 2 & 0 & 0 & 1 & 1 & 0 & 14 & 1 & 29 \\
\hline Setembro & 13 & 2 & 1 & 0 & 0 & 3 & 16 & 6 & 0 & 41 \\
\hline Outubro & 5 & 5 & 2 & 0 & 0 & 0 & 4 & 9 & 0 & 25 \\
\hline
\end{tabular}




\begin{tabular}{|l|c|c|c|c|c|c|c|c|c|c|}
\hline Novembro & 12 & 4 & 0 & 1 & 0 & 9 & 15 & 7 & 0 & 48 \\
\hline Dezembro & 20 & 7 & 0 & 0 & 0 & 1 & 13 & 14 & 0 & 55 \\
\hline TOTAL & 128 & 39 & 9 & 3 & 6 & 45 & 109 & 114 & 2 & 455 \\
\hline
\end{tabular}

Fonte: Elaboração dos autores, 2016.

Analisando as três rodovias federais catarinenses que concentraram $77 \%$ das mortes (BR 101, BR 470 e BR 282), e considerando o número total de acidentes nessas três rodovias, concluímos que a relação morte por acidente é muito maior nas rodovias BR 470 e BR 282, ambas de pista simples, do que na BR 101 (única duplicada do Estado). Apesar de ocorrerem mais acidentes e mais mortes em números absolutos na BR 101, quando se verifica a relação morte por acidente, a BR 101 fica em melhor situação do que as outras duas. Por ser uma rodovia duplicada, os acidentes na BR 101 são menos graves do que nas demais rodovias, já que a colisão frontal praticamente não ocorre na BR 101, por existir uma separação física entre as faixas em sentido contrário e praticamente não haver cruzamento em nível. Nas rodovias de pista simples ocorrem várias colisões frontais, um dos acidentes mais graves envolvendo dois veículos, decorrentes de ultrapassagens em locais proibidos ou invasão da pista contrária, o que pode ocorrer por vários motivos (excesso de velocidade, falta de atenção, sono, embriaguez, etc). Feitas essas considerações, verificamos que a BR 470 é a rodovia federal catarinense que apresenta a maior relação morte por acidente.

BR $101-128$ mortos em 7.101 acidentes $=0,018$ morto por acidente

BR $470-114$ mortos em 2.205 acidentes $=0,051$ morto por acidente

BR $282-109$ mortos em 2.327 acidentes $=0,046$ morto por acidente

Se considerarmos a extensão das três rodovias e o número de acidentes fatais em cada uma, constataremos que, novamente, a BR 470 é a rodovia que apresenta o maior índice de mortalidade. A BR 101 fica em segundo lugar e a BR 282, a rodovia mais longa do Estado, em terceiro lugar.

BR $101-128$ mortos em $465 \mathrm{~km}=0,28$ morto por $\mathrm{km}$

BR 470 - 114 mortos em $358 \mathrm{~km}=0,32$ morto por $\mathrm{km}$

BR $282-109$ mortos em $677 \mathrm{~km}=0,16$ morto por $\mathrm{km}$

A BR 470 é uma rodovia com menos volume diário de veículos do que a BR 101, mas apresenta grande urbanização ao longo do seu trecho, corta uma região extremamente produtiva em Santa Catarina (Vale do Itajaí), passando pela cidade de Blumenau. A rodovia inicia na cidade de Navegantes, que conta com um dos poucos aeroportos do Estado e um dos mais importantes portos do Estado, o que garante grande movimentação de veículos, inclusive de cargas. É uma rodovia também caracterizada por grande número de curvas, aclives e declives e que atualmente encontra-se em projeto de duplicação.

\subsection{Análise de Discurso sob a ótica de Bahktin}

Em relação às mortes de motociclistas, foram registrados 81 acidentes fatais envolvendo motocicletas e motonetas, sendo que 82 motociclistas morreram. Dos 82 motociclistas mortos, 77 eram condutores e 5 (cinco) eram passageiros. $74 \%$ das motos envolvidas em acidentes fatais tinham até 150 cilindradas, ou seja, 
eram motos de pequeno porte, de baixo custo de aquisição e manutenção e, normalmente, usadas diariamente para deslocamento ao trabalho. O levantamento concluiu, ainda, que $68 \%$ dos mortos tinham, no máximo, 40 anos de idade (Tabela 4).

Tabela 4 - Idade e quantidade de motociclistas mortos

\begin{tabular}{|l|c|}
\hline Idade dos motociclistas mortos & $\begin{array}{c}\text { Quantidade de motociclistas } \\
\text { mortos }\end{array}$ \\
\hline Menor de 18 anos & $\begin{array}{c}\text { 03 (dois condutores de 17 } \\
\text { anos e um passageiro) }\end{array}$ \\
\hline Entre 18 e 24 anos & 20 \\
\hline Entre 25 e 30 anos & 13 \\
\hline Entre 31 e 40 anos & 20 \\
\hline Entre 41 e 50 anos & 16 \\
\hline Mais que 50 anos & 10 \\
\hline
\end{tabular}

Fonte: Elaboração dos autores, 2016.

Em relação ao horário dos acidentes fatais envolvendo motos, 59\% ocorreram entre meio-dia e meianoite (Tabela 5). Significativa parcela dos acidentes fatais envolvendo motociclistas ocorre nos períodos vespertino e noturno. Analisando, porém, a tabela abaixo, não se pode inferir que o horário seja determinante das ocorrências, porquanto estas sucedem com certa regularidade ao longo do dia.

Tabela 5 - Horário dos acidentes fatais envolvendo motos

\begin{tabular}{|l|c|}
\hline Horário dos acidentes & $\begin{array}{c}\text { Quantidade de acidentes fatais } \\
\text { com motos }\end{array}$ \\
\hline Entre meia-noite e 05h59 & 18 \\
\hline Entre 06h00 e 11h59 & 15 \\
\hline Entre 12h00 e 17h59 & 24 \\
\hline Entre 18h00 e 23h59 & 24 \\
\hline
\end{tabular}

Fonte: Elaboração dos autores, 2016.

A morte de motociclistas representou, no período analisado, 18\% das mortes ocorridas nas rodovias federais, sendo que $60 \%$ dos motociclistas mortos tinham até 40 anos de idade, ou seja, pessoas jovens, em plena idade produtiva. A maioria das motos envolvidas em acidentes fatais (74\%) são de até 150 cilindradas, consoante estatísticas da PRF.

\subsection{Mortes de Pedestres}

Em relação às mortes de pedestres, durante o ano de 2015 foram registrados 63 atropelamentos nas rodovias federais catarinenses, sendo que 68\% (43) dos pedestres morreram na BR 101, única rodovia duplicada do Estado. A região da Grande Florianópolis foi responsável por 19\% dos atropelamentos fatais. Dos 63 pedestres atropelados e mortos, 53 pedestres foram identificados, sendo constatado que $60 \%$ (32 pedestres) tinham mais que 40 anos de idade (Tabela 6).

Tabela 6 - Idade e quantidade de pedestres mortos 


\begin{tabular}{|l|c|}
\hline Idade dos pedestres mortos & $\begin{array}{c}\text { Quantidade de pedestres } \\
\text { mortos }\end{array}$ \\
\hline Menor de 18 anos & 02 \\
\hline Entre 18 e 24 anos & 05 \\
\hline Entre 25 e 30 anos & 04 \\
\hline Entre 31 e 40 anos & 10 \\
\hline Entre 41 e 50 anos & 20 \\
\hline Mais que 50 anos & 12 \\
\hline
\end{tabular}

Fonte: Elaboração dos autores, 2016.

Da tabela acima apresentada, pode-se inferir que os pedestres menores de idade, por contarem com maior supervisão, não são tão facilmente vítimas de acidentes fatais. Por outro lado, adultos acima de 31 anos são mais comumente vitimados, sendo a faixa etária mais crítica entre 41 e 50 anos.

Em relação ao horário dos acidentes fatais envolvendo pedestres, constatou-se que $77 \%$ dos acidentes fatais ocorreram no período noturno, ou seja, das 18 às 06 horas da manhã (Tabela 7).

Tabela 7 - Horário dos acidentes fatais envolvendo pedestres

\begin{tabular}{|l|c|}
\hline \multicolumn{1}{|c|}{ Horário dos acidentes } & $\begin{array}{c}\text { Quantidade de acidentes } \\
\text { fatais com pedestres }\end{array}$ \\
\hline Entre meia-noite e 05h59 & 13 \\
\hline Entre 06h00 e 11h59 & 07 \\
\hline Entre 12h00 e 17h59 & 07 \\
\hline Entre 18h00 e 23h59 & 36 \\
\hline
\end{tabular}

Fonte: Elaboração dos autores, 2016.

Verifica-se, assim, que os atropelamentos envolvem, na maioria das vezes, pessoas acima de 40 anos e em horário de baixa luminosidade.

Um dos problemas da BR 101 é o grande número de mortes por atropelamento. Ela concentra $68 \%$ das mortes de pedestres atropelados em rodovias federais catarinenses. A duplicação diminuiu a relação morte por acidente em geral, mas aumenta o número de atropelamentos fatais em relação às rodovias de pista simples. A pesquisa demonstrou que 33\% das mortes da BR 101 foram pedestres atropelados.

\subsection{Mortes de Ciclistas}

Em relação às mortes de ciclistas, durante o ano de 2015 foram registrados 22 acidentes fatais envolvendo ciclistas nas rodovias federais catarinenses, sendo que 50\% dos ciclistas morreram na BR 101, única rodovia duplicada do Estado. Outros 23\% dos ciclistas morreram na BR 470, ou seja, essas duas rodovias foram responsáveis por $73 \%$ das mortes dos ciclistas nas rodovias federais do Estado. Dos 22 ciclistas mortos, 21 foram identificados, sendo constatado que $57 \%$ tinham mais que 40 anos de idade (Tabela 8).

Tabela 8 - Idade e quantidade de ciclistas mortos

\footnotetext{
Avaliação do Perfil dos Acidentes Fatais Ocorridos nas Rodovias Federias de Santa Catarina em 2015 e sua Utilização para Direcionar Ações que Visem Reduzir a Violência no Trânsito

Gabriela Almeida Marcon, Luiz Antonio Giardino Graziano, Fernanda Aparecida Da Cunha, Ademar Dutra e Leonardo Ensslin
} 


\begin{tabular}{|l|c|}
\hline Idade dos ciclistas mortos & Quantidade de ciclistas mortos \\
\hline Menor de 18 anos & 01 \\
\hline Entre 18 e 24 anos & 02 \\
\hline Entre 25 e 30 anos & 01 \\
\hline Entre 31 e 40 anos & 05 \\
\hline Entre 41 e 50 anos & 04 \\
\hline Mais que 50 anos & 08 \\
\hline
\end{tabular}

Fonte: Elaboração dos autores, 2016.

A BR-101 está completamente duplicada no Estado de Santa Catarina e, talvez por esta razão seja uma das opções mais comuns dos ciclistas. Ocorre que é uma das mais movimentadas e com velocidade máxima permitida de $110 \mathrm{~km} / \mathrm{h}$ em diversos segmentos.

Em relação ao horário dos acidentes fatais envolvendo ciclistas, constatou-se que $64 \%$ dos acidentes fatais ocorreram no período noturno, ou seja, das 18 às 06 horas da manhã (Tabela 9).

\section{Tabela 9 - Horário dos acidentes fatais envolvendo ciclistas}

\begin{tabular}{|l|c|}
\hline \multicolumn{1}{|c|}{ Horário dos acidentes } & $\begin{array}{c}\text { Quantidade de acidentes } \\
\text { fatais com ciclistas }\end{array}$ \\
\hline Entre meia-noite e 05h59 & 08 \\
\hline Entre 06h00 e 11h59 & 05 \\
\hline Entre 12h00 e 17h59 & 03 \\
\hline Entre 18h00 e 23h59 & 06 \\
\hline
\end{tabular}

Fonte: Elaboração dos autores, 2016.

Verifica-se, assim, que, da mesma forma observada no tocante aos pedestres, a maioria dos acidentes fatais com ciclistas envolvem pessoas acima de 40 anos e em horário de baixa luminosidade. Acidentes fatais com óbito de ciclistas nas rodovias federais de Santa Catarina representaram 5\% do total de mortes.

\subsection{Mortes em Acidentes Envolvendo Veículos de Carga Pesada}

Em relação ao envolvimento de veículos de carga de grande porte em acidentes fatais, a Tabela 2 mostra que do total de 455 mortes ocorridas em 2015 nas rodovias federais de Santa Catarina, 216 mortes (47\%) ocorreram em acidentes com o envolvimento de, pelo menos, um veículo de carga de grande porte (caminhão, carreta, bitrem, etc).

Não foram obtidos e nem aprofundada a pesquisa nesse aspecto, devendo ficar claro que não foi analisada a culpa por esses acidentes. Entretanto, esse dado revela uma situação bastante preocupante na medida em que quase metade das mortes ocorreram em acidentes com participação desse tipo de veículo.

É possível inferir que veículos menores que se envolvem em acidentes com veículos de grande porte sofram maior grau de destruição e dificultem a sobrevivência de seus ocupantes.

\section{Resultados}

A pesquisa buscou discutir o perfil dos 368 acidentes de trânsito fatais ocorridos nas rodovias federais de Santa Catarina no ano de 2015 e propor ações que reduzam esse tipo de acidente. Os dados levantados na pesquisa apontaram que, das 9 (nove) rodovias federais de Santa Catarina, 3 (três) delas são responsáveis por 77\% do total de mortes no Estado - BR 101, BR 470 e BR 282. Estudar os acidentes graves que ocorrem nessas três rodovias propicia a identificação de mecanismos que auxiliem a reduzir significativamente o 
número de acidentes fatais que ocorrem nas rodovias federais de Santa Catarina. Entende-se que estas três rodovias, quais sejam, BR 101; BR 470 e BR 282, devem ser a prioridade de estudos e ações de educação, engenharia e fisscalização no Estado de Santa Catarina, logicamente sem olvidar-se das demais.

Infere-se que no Brasil, as propostas para reduzir a violência no trânsito restringem-se, muitas vezes, a aumentar a punição dos infratores, seja com o acréscimo do valor das multas e outras penalidades administrativas, seja com o recrudescimento das penas dos crimes de trânsito ou criminalização de condutas no trânsito. A punição dos infratores, no âmbito administrativo ou judicial, é importante, mas outras propostas devem ser feitas para reduzir a violência no trânsito.

Logicamente que propostas de redução da violência no trânsito a partir de investimentos nas áreas de engenharia, fiscalização e educação demandam mais recursos, estudos e tempo de implementação do que simplesmente a alteração da legislação para fins de aumento das penalidades e penas por infrações ou crimes de trânsito, ou a criminalização de condutas.

De acordo com as características dos acidentes fatais analisados, podemos concluir que a gravidade dos acidentes em rodovia duplicada é muito menor do que em rodovias de pista simples. A duplicação de uma rodovia não se resume a conforto para o motorista, mas em segurança. Na rodovia duplicada praticamente não existe a colisão frontal, um dos acidentes mais graves envolvendo dois veículos. A relação morte por acidente é muito maior nas rodovias de pista simples do que em rodovia duplicada.

A BR-101 apresenta elevado percentual de mortes por atropelamento. Apesar de não terem sido analisadas as causas desses atropelamentos, essas devem ser investigadas e ações educativas a pedestres que usam a BR 101 devem ser feitas, tendo como público alvo do trabalho educativo pedestres com mais de 40 anos (60\% das mortes por atropelamento) e que usam a rodovia no período noturno (das $18 \mathrm{~h}$ às $6 \mathrm{~h}$ da manhã), o que correspondeu a 77\% dos atropelamentos fatais. Em relação à engenharia, deve ser investigado se o número e a qualidade das passarelas na BR 101 são suficientes e se a iluminação da rodovia em locais onde usualmente ocorre a travessia de pedestres efetivamente existe e se isso não aumentaria a visibilidade dos pedestres e dos veículos e reduziria esse tipo de acidente. Outra causa que está intimamente relacionada com atropelamento de pedestres é o excesso de velocidade em locais onde existe travessia de pedestres. Nesse aspecto a fiscalização desse tipo de infração é uma das medidas que se pode sugerir a fim de reduzir os atropelamentos.

No tocante aos motociclistas, considerando que normalmente pessoas que se encaixam nesse perfil se deslocam diariamente para o trabalho usando a moto como meio de transporte, uma ação propositiva seria elaborar um projeto de educação voltado para esse público específico e para as empresas que possuem empregados que se deslocam de moto e para empresas que usam o serviço de motoboys. Um dos temas que devem ser discutidos com os motociclistas é a necessidade de uso de equipamentos de proteção individual como luva, jaqueta, calça comprida e bota. Em termos de engenharia de trânsito, considerando que a moto é um meio de transporte que é usado por questões de agilidade e economicidade, a melhoria e o incentivo ao uso do transporte coletivo de passageiros, pode ser uma alternativa viável, ao invés da moto. A adoção de faixas exclusivas para motos, com velocidade controlada, em vias de grande movimento e congestionamento, também pode ser uma alternativa a ser analisada pela área de engenharia, considerando que um grande número de motos transita no chamado "corredor" e vários acidentes ocorrem nestas condições.

Em termos de fiscalização, os agentes de trânsito devem priorizar a fiscalização de motos, seja em termos de documentação, manutenção do veículo e infrações de percurso. Em termos legislativos, uma das lacunas que existe, é a não regulamentação do vestuário obrigatório dos motociclistas, o que poderia ser sanado por meio de uma resolução do CONTRAN que definisse o vestuário mínimo obrigatório dos motociclistas e outros equipamentos obrigatórios como antena corta- pipa, colete refletivo, etc.

O levantamento realizado indicou que $73 \%$ das mortes de ciclistas se concentraram nas rodovias BR 101 e BR 470, que 57\% dos mortos tinham mais de 40 anos e que $64 \%$ dos acidentes fatais ocorreram no período noturno (das $18 \mathrm{~h}$ às $06 \mathrm{~h}$ ). O perfil dos ciclistas mortos é muito parecido com o perfil de pedestres

\footnotetext{
Avaliação do Perfil dos Acidentes Fatais Ocorridos nas Rodovias Federias de Santa Catarina em 2015 e sua Utilização para Direcionar Ações que Visem Reduzir a Violência no Trânsito 
mortos. Campanhas educativas para pessoas acima de 40 anos que usam as rodovias, sobretudo a BR $101 \mathrm{e}$ BR 470, podem gerar bons resultados. Um dos assuntos que deve ser abordado é o uso de dispositivos luminosos na bicicleta e de colete refletivo pelos ciclistas. O princípio de direção defensiva "Ver e ser visto" aplica-se totalmente ao tema. Nesse sentido, a iluminação das rodovias próximo aos locais de grande fluxo de ciclistas, melhoria no acostamento e estudo sobre a possibilidade de criação de ciclofaixas ou ciclovias também seriam soluções de engenharia que certamente reduziriam o número de acidentes envolvendo ciclistas. A fiscalização deveria se concentrar em orientar ciclistas quanto ao correto uso da via e, em relação aos veículos automotores, a obrigá-los a respeitar os limites de velocidade impostos.

$\mathrm{O}$ alto envolvimento de veículos de carga pesados em acidentes fatais nas rodovias federais de Santa Catarina exige uma pesquisa mais aprofundada acerca do tema, buscando levantar a responsabilidade pelos acidentes e medidas que possam contribuir para diminuir o envolvimento desse tipo de veículo em acidentes, porquanto, independente da culpa, os acidentes com veículos de grande porte normalmente são graves.

Concluindo, a violência no trânsito nas rodovias federais de Santa Catarina somente irá diminuir se forem feitos estudos sobre as causas de acidentes de trânsito e forem tomadas medidas que abordem a questão de forma multidisciplinar, ou seja, as ações devem ser integradas e concomitantes, abordando os três pilares da segurança no trânsito: Educação, engenharia e fiscalização.

\section{BIBLIOGRAFÍA}

Almeida, N. D. V. D. (2006). Promoção e divulgação de medidas educativas em circulação humana: em questão o fenômeno trânsito. Psicologia Argum., Curitiba, 24(46), 45-53.

Barreto, M. D. S., Teston, E. F., Latorre, M. D. R. D. D., Mathias, T. A. D. F., Marcon, S. S. (2016). Mortalidade por acidentes de trânsito e homicídios em Curitiba, Paraná, 1996-2011. Epidemiologia e Serviços de Saúde, 25(1), 95-104.

Beck, Laurie F.; Dellinger, Ann M.; O'neil, Mary E. (2007). Motor vehicle crash injury rates by mode of travel, United States: using exposure-based methods to quantify differences. American Journal of Epidemiology, v. 166, n. 2, p. 212218.

Brasil. Presidência da República. Casa Civil. (1988) Constituição da República Federativa do Brasil, 05 de outubro de 1988. Brasília. Disponível em:<www.planalto.gov.br/ccivil_03/constituicao/ConstituicaoCompilado.htm>. Acesso em 12 jun. 2016.

Brasil. Presidência da República. Casa Civil. (1998) Lei Federal n. 9.654, de 02 de junho de 1998. Cria a carreira de Policial Rodoviário Federal e dá outras providências. Disponível em: $<$ http://www.planalto.gov.br/ccivil_03/LEIS/L9654compilado.htm>. Acesso em 12 jun. 2016.

Brasil. Presidência da República. Casa Civil. (1997). Lei Federal n. 9.503, de 23 de setembro de 1997: Institui o Código de Trânsito Brasileiro. Disponível em: < http://www.planalto.gov.br/ccivil_03/LEIS/L9503.htm>. Acesso em 12 jun. 2016.

Brasil. Ministério da Justiça. Departamento de Polícia Rodoviária Federal. (2015). Página Inicial. Conheça a PRF. Disponível em: < https://www.prf.gov.br/PortalInternet/conhecaPRF.faces>. Acesso em 12 jun. 2016.

Brasil. Portal Brasil. (2015). Brasil reduz em 5,7\% número de mortes no trânsito. Disponível em <http://www.brasil.gov.br/saude/2015/11/infografico-18-11-seguranca-no-transito.png/view>. Acesso em 29 jun.2016.

Bull, J. P.; Roberts, Benjamin J. (1973). Road accident statistics: a comparison of police and hospital information. Accident Analysis \& Prevention, v. 5, n. 1, p. 45-53.

De Deus, Jardel. S. (2015). Os direitos fundamentais, a sociedade do risco e a (in) eficiência da expansão do direito penal como forma de diminuição da criminalidade na era globalizada. Disponível em: <www.derechoycambiosocial.com/revista042/OS_DIREITOS_FUNDAMENTAIS.pdf> Acesso em 15 set. 2016. 
De Oliveira, G. F., Batista, H. M. T., Rufato De Oliveira, D., Maranhão, T. L. G., Braga, I. B., Guedes, J. D. (2015). Psicologia do Trânsito: Uma Revisão Sistemática. Cadernos de Cultura e Ciência, 13(2), 124-145.

De Palma, A., Kilani, M., Lindsey, R. (2008). The merits of separating cars and trucks. Journal of Urban Economics, 64(2), 340-361.

DENATRAN. Anuário estatístico. 2006. Disponível em <http://www.viasseguras.com/os_acidentes/estatisticas/estatisticas_nacionais/estatisticas_do_denatran/anuarios_estatisticos_do_den atran/anuario_do_denatran_acidentes_2006>. Acesso em 15 jun. 2016.

Instituto de Salud Carlos III. (2013). Mortalidad. España y Comunidades Autónomas. Madrid. Disponível em $<\mathrm{http}: / /$ www.isciii.es/ISCIII/es/contenidos/fd-servicioscientifico-tecnicos/fd-vigilancias-alertas/mortalidad-cne.shtml>. Acesso em 18 jun. 2016.

Folha de São Paulo. Mortes em rodovias federais têm menor índice desde 2007. Disponível em $<$ http://www1.folha.uol.com.br/cotidiano/2016/04/1761527-mortes-em-rodovias-federais-tem-menor-indice-desde2007.shtml>. Acesso em 15 jun. 2016.

Fonseca, R. M. (2016). Análise das principais causas de acidentes de trânsito com vítimas investigadas em algumas cidades da região sul do Tocantins. Disponível em <http://www.sindiperito.org.br/artigos-18-analise-das-principaiscausas-de-acidentes-de-transito-com-vitimas-investigadas-em-algumas-cidades-d>. Acesso em 25 jun. 2016.

Goode, William J.; Hatt, Paul K. (1968). Métodos em pesquisa social. 2. ed. São Paulo: Nacional.

Harrison, Marissa A. (2011). College students' prevalence and perceptions of text messaging while driving. Accident Analysis \& Prevention, v. 43, n. 4, p. 1516-1520.

Hoff, J., Grell, J., Lohrman, N., Stehly, C., Stoltzfus, J., Wainwright, G., Hoff, W. S. (2013). Distracted driving and implications for injury prevention in adults. Journal of Trauma Nursing, 20(1), 31-34.

Horne, Jim; Reyner, Louise. (1999). Vehicle accidents related to sleep: a review. Occupational and Environmental Medicine, v. 56, n. 5, p. 289-294.

Lakatos, Eva Maria; Marconi, Marina de Andrade. (2003). Fundamentos de metodologia científica. 5. ed. São Paulo: Atlas.

Limpert, Rudolf. (1984). Motor vehicle accident reconstruction and cause analysis.

Martins, H. H. (2004). Metodologia Qualitativa de Pesquisa. Educação e Pesquisa, São Paulo, v.30, n.2, p. 289-300, maio/ago.

Melchor, I., Nolasco, A., Moncho, J., Quesada, J. A., Pereyra-Zamora, P., García-Senchermés, C., Salinas, M. (2015). Trends in mortality due to motor vehicle traffic accident injuries between 1987 and 2011 in a Spanish region (Comunitat Valenciana). Accident Analysis \& Prevention, 77, 21-28.

Miaou, Shaw-Pin; Lum, Harry. (1993). Modeling vehicle accidents and highway geometric design relationships. Accident Analysis \& Prevention, v. 25, n. 6, p. 689-709.

Nações Unidas No Brasil. (2011). Década de Ação pela Segurança no Trânsito 2011 - 2020 é lançada oficialmente hoje (11) em todo o mundo. Disponível em <https://nacoesunidas.org/decada-de-acao-pela-seguranca-no-transito-20112020-e-lancada-oficialmente-hoje-11-em-todo-o-mundo/>. Acesso em 15 jun. 2016.

Nemme, Heidi E.; White, Katherine M. (2010). Texting while driving: Psychosocial influences on young people's texting intentions and behaviour. Accident Analysis \& Prevention, v. 42, n. 4, p. 1257-1265.

Rodrigues, C. L., De Eston Armond, J., Gorios, C., Souza, P. C. (2014). Acidentes que envolvem motociclistas e ciclistas no município de São Paulo: caracterizacão e tendências. Revista Brasileira de Ortopedia, 49(6), 602-606.

Rowe, R., Roman, G. D., Mckenna, F. P., Barker, E., Poulter, D. (2015). Measuring errors and violations on the road: A bifactor modeling approach to the Driver Behavior Questionnaire. Accident Analysis \& Prevention, v. 74, p. 118-125.

Selzer, Melvin L.; Rogers, Joseph E.; Kern, Sue. (1968). Fatal accidents: The role of psychopathology, social stress, and acute disturbance. American Journal of Psychiatry, v. 124, n. 8, p. 1028-1036.

Avaliação do Perfil dos Acidentes Fatais Ocorridos nas Rodovias Federias de Santa Catarina em 2015 e sua Utilização para Direcionar Ações que Visem Reduzir a Violência no Trânsito

Gabriela Almeida Marcon, Luiz Antonio Giardino Graziano, Fernanda Aparecida Da Cunha, Ademar Dutra e Leonardo Ensslin 
Tondo, A. L., Scheuermann, G. F., Rodrigues, L., Werle, V. M., Tonetto, V. H. (2014). Antagonismo entre o Aumento das Penas e a Redução da Criminalidade no Brasil. (Re) Pensando Direito,4(7), 265-284.

USP - Agência USP de Notícias. (2016). Pesquisa traça panorama dos acidentes de trânsito no Brasil. São Paulo. 4 de janeiro de 2016. Disponível em: < http://www5.usp.br/103087/pesquisa-traca-panorama-dos-acidentes-de-transito-nobrasil/>. Acesso em 15.06.2017.

Wilson, Fernando A.; Stimpson, Jim P. (2010). Trends in fatalities from distracted driving in the United States, 1999 to 2008. American Journal of Public Health, v. 100, n. 11, p. 2213-2219.

World Health Organisation - WHO (2009). Global status report on road safety: time for action. Geneva. Disponível em $<$ http://www.who.int/violence_injury_prevention/road_safety_status/2009>. Acesso em 15 jun. 2016.

World Health Organisation - WHO. (2013). Global Status Report on Road Safety 2013: Supporting a Decade of Action. World Health Organisation, Geneva, Switzerland. 